\title{
Exploring thermosonication as non-chemical disinfection technology for strawberries
}

\author{
Iolanda Nicolau-Lapeña ${ }^{1} \cdot$ Ingrid Aguiló-Aguayo ${ }^{2} \cdot$ Marina Anguera $^{2} \cdot$ Inmaculada Viñas $^{1} \cdot$ Maribel Abadias $^{2}$
}

Received: 23 August 2021 / Revised: 3 November 2021 / Accepted: 7 November 2021 / Published online: 27 November 2021

(c) The Author(s) 2021

\begin{abstract}
The scope of this work was to study the efficacy of the combination of sonication at 35 or $130 \mathrm{kHz}$ with three temperature treatments: 20,50 and $55^{\circ} \mathrm{C}$, on the population of artificially inoculated Listeria innocua in strawberries, and on their overall quality. Prior in vitro results showed that temperature was the main factor in decreasing L. innocua population: a maximum of $3.8 \log$ reductions was obtained with sonication at $130 \mathrm{kHz}$ and $55^{\circ} \mathrm{C}$ for $15 \mathrm{~min}$ Treatments combining —or not—sonication at $130 \mathrm{kHz}$ with mild temperatures $\left(50\right.$ and $\left.55^{\circ} \mathrm{C}\right)$ for 5 or $10 \mathrm{~min}$ were able to decrease about $3 \log$ units of artificially inoculated L. innocua in strawberries and about $2 \log$ units of total aerobic mesophilic and yeasts and molds populations naturally occurring in strawberries. Thermosonication treatments did not exert a detrimental impact on fruit quality, except for those at the higher temperatures and times, which caused a change in color to more purplish and a little softening of the strawberries, which were proposed to be assessed for further processing other than fresh commercialization. Overall, the impact of sonication in fresh strawberries needs to be further investigated to find the adequate conditions to enhance the effects of temperature itself.
\end{abstract}

Keywords Antioxidant $\cdot$ Epiphytic microbiota $\cdot$ Fresh fruit $\cdot$ Listeria innocua $\cdot$ Quality $\cdot$ Ultrasound

\begin{tabular}{ll}
\multicolumn{2}{l}{ Abbreviations } \\
AAE & Ascorbic acid equivalents \\
DPPH & 2,2-Diphenyl-1-picrylhydrazyl \\
DRBC & Dichloran rose bengale chloramphenicol agar \\
FRAP & Ferric reducing antioxidant power \\
FW & Fresh weight \\
GAE & Gallic acid equivalents \\
PCA & Plate count agar \\
TAM & Total aerobic mesophylls \\
TCEP & $3,3^{\prime}, 3^{\prime \prime}-$ Phosphanetriyltripropanoic acid \\
TAC & Total anthocyanin content \\
TPC & Total phenolic content \\
TPTZ & $2,4,6-$ Tris(2-pyridyl)-s-triazine \\
Y\&M & Yeasts and moulds
\end{tabular}

Maribel Abadias

isabel.abadias@irta.cat

1 Food Technology Department, Agrotecnio-Center, University of Lleida, Rovira Roure 191, 25198 Lleida, Catalonia, Spain

2 IRTA, Postharvest Programme, Edifici Fruitcentre, Parc Científic i Tecnològic Agroalimentari de Lleida, Parc de Gardeny, 25003 Lleida, Catalonia, Spain

\section{Introduction}

Precis

- In vitro thermosonication $\left(130 \mathrm{kHz}\right.$ and $55^{\circ} \mathrm{C}$ for $\left.15 \mathrm{~min}\right)$ reduced L. innocua 2.5 logs.

- L. innocua was artificially inoculated in strawberries before sonication.

- L. innocua population in strawberries decreased up to 2.6 logs after thermosonication.

- Best treatments were sonication $(130 \mathrm{kHz})$ at 50 for $10 \mathrm{~min}$ or $55^{\circ} \mathrm{C}$ for $5 \mathrm{~min}$.

- Thermosonicated strawberries did not overcome major quality losses.

Sonication consists on the use of ultrasonic waves at a frequency beyond $18 \mathrm{kHz}$ with a specific intensity and amplitude [1]. Microorganism lethality caused by sonication is attributed to transient cavitation, a phenomenon consisting of a large number of microscopic bubbles that originate from cycles of pressure [2]. The collapse of generated bubbles causes spots with extremely high pressure and temperature, destroying the cellular envelopes and other components; thus, reducing the viable microorganisms [3]. Also, if fresh 
and fresh-cut fruits are treated with ultrasounds, chemical and structural changes affecting quality and nutritional values of the product may occur [3]. However, as reviewed by Nicolau-Lapeña, Lafarga, et al. [4], it is necessary to combine ultrasounds with other physical or chemical methods to achieve successful sanitation of fresh and fresh-cut fruits. In particular, thermosonication, or the combination of heat with ultrasounds, is one of the most effective approaches to inactivate microbes for industrial purposes [5]. When ultrasounds are combined with heat, the rate of sterilization of foods can be accelerated; thus, lessening both the duration and intensity of thermal treatment and the resultant damage. The advantages of ultrasound over heat pasteurization include: the minimizing of flavor loss, especially in sweet juices; greater homogeneity; and significant energy and cost savings [6].

The need for sanitation procedures in fresh fruit industry becomes evident in the many foodborne illnesses and outbreaks occurring annually [7]. Additionally, several outbreaks caused by Listeria monocytogenes have been recently linked to fresh produce contamination around the world [8]. Listeriosis is causing from mild gastroenteritis to severe disease conditions (septicemia, encephalitis, meningitis, abortions and stillbirths) and resulting in a high fatality rate in immune-compromised populations [9]. Inactivation of L. monocytogenes has already been described in other studies, both in vitro [10] and in vivo in different products such as milk [11] and fruit juices [12]. Although strawberries are considered a low risk product, Flessa, Lusk, \& Harris [13] demonstrated that L. monocytogenes was capable of surviving but not growth on the surface of fresh intact or cut strawberries throughout the expected shelf life. Growth of $L$. monocytogenes has been demonstrated in a number of vegetables under refrigerated and ambient and in non-acidic fruits [14]. Growth has also been demonstrated on the outer surface of acidic fruits such as tomatoes [15] and peeled oranges [16] when stored at greater than $20^{\circ} \mathrm{C}$.

In this paper, sonication and thermosonication effects on the survival of L. innocua (used as a L. monocytogenes surrogate) were investigated both in vitro and in vivo in strawberries, as well as their impact on quality parameters of the treated fruits, to produce safer products while maintaining their quality.

\section{Materials and methods}

\section{Materials}

Strawberries (Fragaria $\times$ ananassa) were purchased from local providers the same day of the experiment, and stored at $4{ }^{\circ} \mathrm{C}$ until it was carried out. Strawberries with no visible damages and similar in size were selected, and peduncle was removed.

Triptone soy broth (TSB), triptone soy agar (TSA), Palcam base agar and Palcam selective supplement for Listeria spp., yeast extract, plate count agar (PCA), dichloran rose bengale chloramphenicol agar (DRBC), sodium chloride and peptone were obtained from Biokar Diagnostics (Allonne, France). Dey-Engley broth was obtained from Honeywell Fluka (Madrid, Spain).

2,4,6-tris (2-pyridyl) -s-triazine (TPTZ), 2,2-diphenyl1-picrylhydrazyl (DPPH), and sodium carbonate were acquired from Sigma-Aldrich (Steinheim, Germany). Methanol, chlorhidric acid (37\%), sodium acetate, sodium hydroxide, ferric chloride hexahydrate and Folin Ciocalteau's reagent were procured from Panreac (Llinars del Vallès, Spain).

\section{Methods}

\section{Listeria innocua culture preparation}

Listeria innocua strain CECT-910 (Colección Española de Cultivos Tipo, Burjassot, Spain) was used as an innocuous surrogate of L. monocytogenes in this study [17, 18]. Cultures were prepared as described in Nicolau-Lapeña et al. [4], and the concentrated suspension obtained contained $1.2 \times 10^{10} \mathrm{CFU} \mathrm{mL}^{-1}$, approximately.

\section{Survival curves of $L$. innocua under different combinations of temperature and sonication}

The inactivation of L. innocua when exposed to mild temperatures $\left(50\right.$ and $\left.55^{\circ} \mathrm{C}\right)$ combined or not with sonication ( 35 or $135 \mathrm{kHz}$ ) was investigated and compared to the behavior of L. innocua at $20^{\circ} \mathrm{C}$, also combined or not with sonication. For this, $500 \mathrm{~mL}$ of sterile water were prepared in a glass beaker (3 replicates) were immersed in a TRANSSONIC TI-H-20 bath (Elma Schmidbauer GmbH, Singen, Germany) set to the selected temperature. Once the water in the beaker had reached the studied temperature, an adequate volume of the prepared $L$. innocua suspension was added to reach a concentration of $10^{7} \mathrm{CFU} \mathrm{mL}{ }^{-1}$. Nine different treatments were carried out twice (two replicates), combining three temperatures $\left(20,50\right.$, or $\left.55^{\circ} \mathrm{C}\right)$ with three sonication conditions (no sonication, sonication at $35 \mathrm{kHz}$ or $130 \mathrm{kHz}$ ) during $15 \mathrm{~min}$. For each sampling time $(0,1,2,5$, and $15 \mathrm{~min}), 5 \mathrm{~mL}$ of each repetition were poured in a sterile tube, and $1 \mathrm{~mL}$ was added to $9 \mathrm{~mL}$ of Dey-Engley media to evaluate the presence or absence of L. innocua. Tubes were immediately cooled by immersion in water iced. An additional beaker with $500 \mathrm{~mL}$ of water was used to monitor the temperature using a DualTemp Pro Insertion-Infrared Thermometer (Dostmann, Reicholzheim, Germany). 
Survival of $L$. innocua artificially inoculated in strawberries under different combinations of temperature and sonication

The effect of the combination of sonication at $130 \mathrm{kHz}$ with mild temperature $\left(50\right.$ and $55^{\circ} \mathrm{C}$, thermosonication) was evaluated and compared to the effect of sonication at $130 \mathrm{kHz}$ at $20^{\circ} \mathrm{C}$. For this, strawberries were inoculated the day before the assay with a suspension containing $10^{10} \mathrm{CFU} \mathrm{mL} \mathrm{m}^{-1}$ of $L$. innocua, by pipetting $50 \mu \mathrm{L}$ in small droplets on the surface. Once dried, strawberries were disposed in plastic alveoli and stored in non-hermetic plastic boxes overnight in at $4 \pm 1{ }^{\circ} \mathrm{C}$ to avoid excessive maturation. Prior to the treatments, strawberries were let to reach room temperature for $2 \mathrm{~h}$.

Six treatments were performed, combining three temperatures $\left(20,50\right.$, and $\left.55^{\circ} \mathrm{C}\right)$ and two sonication conditions (with and without sonication). For this, $500 \mathrm{~mL}$ of water were poured in each of the four glass beakers, which were immersed in the ultrasonic bath (TRANSSONIC TI-H-20) set to the selected temperature. Once the water reached the studied temperature, 12 strawberries were simultaneously immersed on it. Each sampling time (1, 2, 5, or $10 \mathrm{~min}), 3$ strawberries were collected from one beaker using a net and immersed in chilled water for $10 \mathrm{~s}$, to lower the temperature and avoid further L. innocua inactivation. Strawberries were let to dry at room temperature on disinfected grids. Also, $5 \mathrm{~mL}$ of water were poured in a sterile tube to count L. innocua that could have been dragged to water, and $1 \mathrm{~mL}$ was added to $9 \mathrm{~mL}$ of Dey-Engley media to evaluate the presence or absence of $L$. innocua in wash water. To prevent further population changes, tubes were kept in ice until count procedure. This experiment was carried out twice ( 2 replicates, $n=6$ ).

\section{Determination of $L$. innocua population}

L. innocua population in the suspension or in water. Concentration of $L$. innocua after the treatments was determined by serially dilution in saline peptone (SP, peptone $1 \mathrm{~g} \mathrm{~L}^{-1}$ and $\mathrm{NaCl}, 8.5 \mathrm{~g} \mathrm{~L}^{-1}$ ) and plating in TSAYE (triptone soy agar supplemented with $6 \mathrm{~g} \mathrm{~L}^{-1}$ of yeast extract, $2.5 \mathrm{~g} \mathrm{~L}^{-1}$ glucose and $2.5 \mathrm{~g} \mathrm{~L}^{-1} \mathrm{~K}_{2} \mathrm{HPO}_{4}$ ) for concentrate suspension, or in selective Palcam agar for both, concentrate suspension and studied water. Plates were incubated at $37 \pm 1{ }^{\circ} \mathrm{C}$ for $22 \pm 2 \mathrm{~h}$ for TSAYE and $48 \pm 2 \mathrm{~h}$ for Palcam. Results were expressed as $\log \mathrm{CFU} \mathrm{mL} \mathrm{mL}^{-1}$. When counts were below the limit of detection (0.7 log units), and presence was confirmed by Dey-Engley color change after incubation at $37 \pm 1^{\circ} \mathrm{C}$ for 24 or $48 \mathrm{~h}$, an arbitrary value of half detection limit of detection was assigned.

L. innocua population in strawberries. One strawberry per replicate was used for microbiological analysis (three repetitions per treatment, two replications of the experiment, $n=6$ ). Populations were determined by plate count on selective Palcam medium in duplicate, as it has been previously described in [19]. Results were expressed as $\log$ CFU fruit ${ }^{-1}$, and detection limit was $1.3 \log$ units.

\section{Evaluation of the effect of selected combinations of temperature and sonication in strawberry quality parameters}

Based on the results previously obtained, the following treatments were selected to study their effect on fruit quality: sonication and non-sonication at $50{ }^{\circ} \mathrm{C}$ for 5 and $10 \mathrm{~min}$, and sonication and non-sonication at $55{ }^{\circ} \mathrm{C}$ for $5 \mathrm{~min}$. Results were compared with non-sonicated treatments at $20^{\circ} \mathrm{C}$ for 5 and $10 \mathrm{~min}$. Treatments were performed as described in Sect. 2.2.3., using 12 non-inoculated strawberries per repetition, and when the fruits were dry, the following quality determinations were performed: total aerobic mesophylls (TAM), yeasts and molds (Y\&M), firmness and color. Also, whole strawberries were frozen with liquid nitrogen, milled using a MINIMOKA GR-020 grinder (Taurus Group, Barcelona, Spain) and stored at $-80^{\circ} \mathrm{C}$ for further biochemical analysis: antioxidant capacity, total phenolic content (TPC) and total anthocyanin content (TAC). The experiment was performed once, with three repetitions $(n=3)$.

Epiphytic microbiota For the determination of total aerobic mesophylls (TAM) and yeasts and molds (Y\&M), 25 $\pm 1 \mathrm{~g}$ per repetition $(n=3)$, taken from pieces of two strawberries, were diluted 1:10 in peptone buffered solution in a sterile filter bag (BagPage ${ }^{\circledR}$, Interscience BagSystem, Saint Nom, France) and homogenized in a paddle blender for $90 \mathrm{~s}$ at 9 stroke $\mathrm{s}^{-1}$. Aliquots were serially diluted in SP. For TAM, samples were plated in PCA and incubated at $30 \pm 1{ }^{\circ} \mathrm{C}$ for 3 days. For Y\&M, samples were plated in DRBC and incubated at $25 \pm 1^{\circ} \mathrm{C}$ for 5 days. Results were expressed as log $\mathrm{CFU} \mathrm{g}^{-1}$, and detection limit was $1.7 \log \mathrm{CFU} \mathrm{g}{ }^{-1}$.

Firmness and color Firmness changes were evaluated on ten strawberries per repetition $(n=3)$ using the TA.XT Plus Connect texture analyzer (Stable Micro systems Ltd., Surrey, England). Compression test consisted of compressing a strawberry half to $6.0 \mathrm{~mm}$ using two parallel plates, and recording the maximum force required. Penetration test was performed with a $4 \mathrm{~mm}$ cylindrical probe, measuring the maximum force encountered when the probe when entering $8.0 \mathrm{~mm}$ deep into the tissue. Both tests were run at $5 \mathrm{~mm} / \mathrm{s}$ speed with a trigger force of $0.1 \mathrm{~N}$.

Color of ten strawberries per repetition $(n=3)$ was measured on three points of each sample using a CR-200 Minolta Chroma Meter (Minolta, INC., Tokyo, Japan) with a D65 illuminant and $10^{\circ}$ observer angle. The instrument was 
calibrated using a standard white reflector plate. Color is expressed as CIE L* a* b* coordinates.

Biochemical analysis Biochemical analysis was performed on aliquot samples, previously milled and frozen, and stored at $-80{ }^{\circ} \mathrm{C}$ until use.

Antioxidant activity of strawberries was assessed by ferric reducing antioxidant power (FRAP) and DPPH scavenging activity assays. For the extraction, $3.0 \pm 0.1 \mathrm{~g}$ were mixed with $10 \mathrm{ml}$ of methanol $70 \%(\mathrm{v} / \mathrm{v})$ and homogenized in a vortex for $20 \mathrm{~s}$. Samples were immediately placed in a stirrer at $4{ }^{\circ} \mathrm{C}$ working at $195 \mathrm{rpm}$ for $5 \mathrm{~min}$ and centrifuged using a Sigma-3-18 KS centrifuge (Sigma Laborzentrifugen $\mathrm{GmbH}$, Osterode am Harz, Germany) at $13500 \times g$ for $20 \mathrm{~min}$ at $4{ }^{\circ} \mathrm{C}$. Supernatant was then filtered and marked to $12.5 \mathrm{~mL}$ with methanol $70 \%$. The FRAP reagent was prepared with a mixture of acetate buffer $0.3 \mathrm{M} \mathrm{pH} 2.6$, TPTZ $40 \mathrm{mM}$ in $\mathrm{HCl}$ and $\mathrm{FeCl}_{3} \cdot 6 \mathrm{H}_{2} \mathrm{O} 20 \mathrm{mM}$ in distilled water in 10:1:1 (v:v:v) proportion. The determination was performed by adding $0.1 \mathrm{~mL}$ of the extract to $1.4 \mathrm{~mL}$ of FRAP reagent and incubating in a thermostatic bath at $37{ }^{\circ} \mathrm{C}$ for $20 \mathrm{~min}$ in the dark. Absorbance was read at $593 \mathrm{~nm}$ using GENESYS ${ }^{\mathrm{TM}}$ 10S UV-Vis spectrophotometer (Thermo Fisher Scientific, MA, USA).

DPPH - radical was prepared daily by diluting a stock solution of DPPH. $1 \mathrm{mM}$ in methanol $100 \%$, until an absorbance at $515 \mathrm{~nm}$ of $0.750 \pm 0.50$ was reached. Then, the determination was performed by adding $0.1 \mathrm{~mL}$ of the extract to $1.4 \mathrm{~mL}$ of DPPH. reagent and incubating at RT for $1 \mathrm{~h}$ in the dark. Absorbance was read at $515 \mathrm{~nm}$ using GENESYS ${ }^{\mathrm{TM}}$ 10S UV-Vis spectrophotometer (Thermo Fisher Scientific, MA, USA).

Standard curves with ascorbic acid for both methods were prepared daily using the same procedure as with the samples. Results were expressed as ascorbic acid equivalents in $\mathrm{g} \mathrm{kg}^{-1}$, in FW basis of three repetitions $(n=3)$.

The total phenolic content (TPC) was assessed by Folin Ciocalteau method on the same extract used for antioxidant activity determination. The assay was performed by adding $4.3 \mathrm{~mL}$ of distilled water and $0.5 \mathrm{~mL}$ of Folin-Ciocalteu's reagent to $0.7 \mathrm{~mL}$ of extract. After shaking and incubation for $5 \mathrm{~min}$ at RT in the dark, $2 \mathrm{~mL}$ of saturated sodium carbonate were added. The mixture was again shaken and incubated for $1 \mathrm{~h}$ in the dark. Absorbance was read at $760 \mathrm{~nm}$ using GENESYS ${ }^{\mathrm{TM}}$ 10S UV-Vis spectrophotometer (Thermo Fisher Scientific, MA, USA). Standard curve with gallic acid was prepared daily using the same procedure as with the samples. Results were expressed as gallic acid equivalents in $\mathrm{g} \mathrm{kg}^{-1}$, in $\mathrm{FW}$ basis of three repetitions $(n=3)$.

Anthocyanin extracts and quantification were carried out in triplicate $(n=3)$ according to the method described by Meyers et al. [20]. Briefly, $5.0 \pm 0.1 \mathrm{~g}$ of frozen sample were mixed with $10 \mathrm{~mL}$ of methanol $80 \%(\mathrm{v} / \mathrm{v})$ and vortexed for $20 \mathrm{~s}$. After stirring at $200 \mathrm{rpm}$ for $10 \mathrm{~min}$ at $4{ }^{\circ} \mathrm{C}$, the mixture was centrifuged using a Sigma-3-18 KS centrifuge (Sigma Laborzentrifugen GmbH, Osterode am Harz, Germany) at $12,000 \mathrm{rpm}$ for $15 \mathrm{~min}$ at $4{ }^{\circ} \mathrm{C}$. Supernatant was then filtered and stored at $-80^{\circ} \mathrm{C}$ until needed.

Determination was accomplished by adding a $0.5 \mathrm{~mL}$ aliquot of the extract to potassium chloride buffer $0.025 \mathrm{M}$, $\mathrm{pH} 1.0$ and also to sodium acetate buffer $0.400 \mathrm{M}, \mathrm{pH} 4.5$ to a final volume of $5 \mathrm{~mL}$. Absorbance of both solutions was read at 510 and $700 \mathrm{~nm}$. For quantification, Eq. 2 was used:

$\Delta A=\left(A_{510}-A_{700}\right)_{p H 1.0}-\left(A_{510}-A_{700}\right)_{p H 4.5}$,

where $\mathrm{A}$ is absorbance at a certain wavelength. Anthocyanin content was expressed as cianidine-3-glucosyde in $\mathrm{g} \mathrm{kg}^{-1}$, in FW basis, following the calculations described in Meyers et al., [20].

\section{Statistical analysis}

All data were checked for significant differences by applying analysis of variance test (ANOVA). For in vitro studies, a three-way ANOVA was performed, whereas for in vivo studies, a one-way ANOVA was used. The criterion for statistical significance was $p<0.05$. When significant differences were observed, Tukey's honest significant difference (HSD) of the means was applied $(p<0.05)$. All statistical analyses were carried on using JMP 13 (SAS Institute Inc., Cary, USA).

\section{Results}

\section{Survival curves of $L$. innocua under different combinations of temperature and sonication}

Initial population of L. innocua in the water suspension was $7.2 \pm 0.1 \log \mathrm{CFU} \mathrm{mL} \mathrm{m}^{-1}$ (Fig. 1). At $20^{\circ} \mathrm{C}$ (Fig. 1A), no changes during sonication for $15 \mathrm{~min}$ were observed, either at 35 or at $130 \mathrm{kHz}$. Similarly, at $50^{\circ} \mathrm{C}$ (Fig. 1B), population did not significantly change during the $15 \mathrm{~min}$ treatment, regardless of sonication conditions. The survival curves at $55^{\circ} \mathrm{C}$ (Fig. 1C) were significantly different from those at 20 and $50^{\circ} \mathrm{C}$ from $\min 2$, when population of L. innocua started to decrease. Inactivation was more acute after $15 \mathrm{~min}$, reaching final population of $3.8 \pm 0.9 \log \mathrm{CFU} \mathrm{mL} \mathrm{mL}^{-1}$ in non-sonicated and sonicated at $130 \mathrm{kHz}$ treatments. When the two ultrasound conditions combined with $55^{\circ} \mathrm{C}$ were compared, $130 \mathrm{kHz}$ showed higher efficacy than $35 \mathrm{kHz}$ did (final populations of $3.2 \pm 0.3$ and $4.8 \pm 0.1 \log \mathrm{CFU} \mathrm{mL} \mathrm{m}^{-1}$, respectively). However, the ANOVA test revealed that 'Ultrasound' was not a significant factor, being significant factors 'Temperature' and the interaction of 'Temperature $\times$ Time'. 

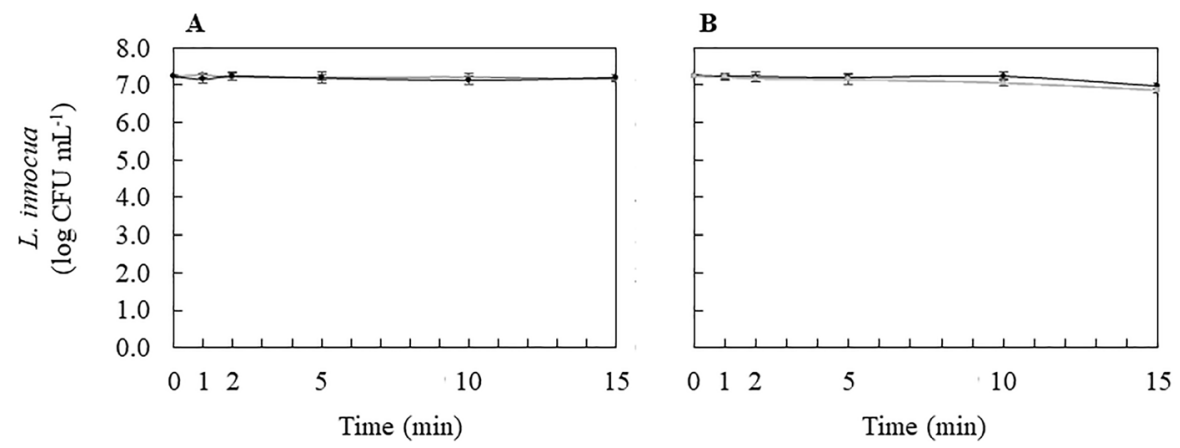

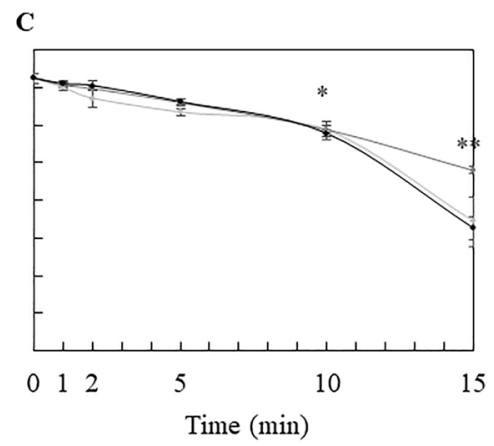

Fig. 1 Survival curves of Listeria innocua in water at $20{ }^{\circ} \mathrm{C}$ (A), $50{ }^{\circ} \mathrm{C}(\mathrm{B})$, and $55{ }^{\circ} \mathrm{C}(\mathrm{C})$ without sonication (black), sonication at $35 \mathrm{kHz}$ (dark grey) or sonication at $130 \mathrm{kHz}$ (grey). Values are the mean \pm standard deviation $(n=3)$. Asterisk mark represents sampling times at which the population significantly decreased $(p<0.05)$ in comparison to the previous treatments according to Tukey's HSD test

\section{Reductions of $L$. innocua artificially inoculated in strawberries under different combinations of temperature and sonication}

Initial population of $L$. innocua in strawberries was $7.2 \pm$ $0.4 \log$ CFU fruit ${ }^{-1}$ after overnight storage at $4{ }^{\circ} \mathrm{C}$ (data not shown). After $2 \mathrm{~min}$, L. innocua population was significantly reduced at least $2.0 \log$ units by all combinations of temperature and sonication conditions (Figure 2). At $20^{\circ} \mathrm{C}$, a significant difference attributed to sonication was revealed in L. innocua reductions after $15 \mathrm{~min}$, which was $1.8 \pm 0.8$ and $3.0 \pm 0.7 \log \mathrm{CFU}$ fruit $^{-1}$ in non-sonicated and sonicated samples, respectively. At 2 min of treatment, there were marked differences between sonicated and non-sonicated samples at 50 and $55^{\circ} \mathrm{C}$. While non-sonicated samples had a decrease in population of $4.8 \pm 1.5 \log \mathrm{CFU}$ fruit $^{-1}$, the population decreased one more log when sonication was combined with the mild temperatures, achieving 6.0 $\pm 1.4 \log$ CFU fruit ${ }^{-1}$ reductions. However, the impact of ultrasound was concealed in the following times at the mild temperatures studied, factor that was more significant than ultrasound did. Figure 3 shows the aspect of strawberries after the treatments.

Regarding population of L. innocua that was transferred to water (Figure 4), no difference was found between sonication and non-sonication treatments, and the differences in viable populations could essentially be attributed to the temperature. At $20^{\circ} \mathrm{C}$ and after 2 min treatment $L$. innocua population in the wash water was $4.3 \pm 0.5$ and $3.5 \pm 1.0$ $\log \mathrm{CFU} \mathrm{mL} \mathrm{m}^{-1}$ in non-sonicated and sonicated treatments, respectively. After $15 \mathrm{~min}$, population decreased to $2.4 \pm$ 0.8 and $1.7 \pm 0.4 \log \mathrm{CFU} \mathrm{mL}{ }^{-1}$. However, the final population in water was similar regardless the sonication treatment. Significantly lower L. innocua counts in washing water were

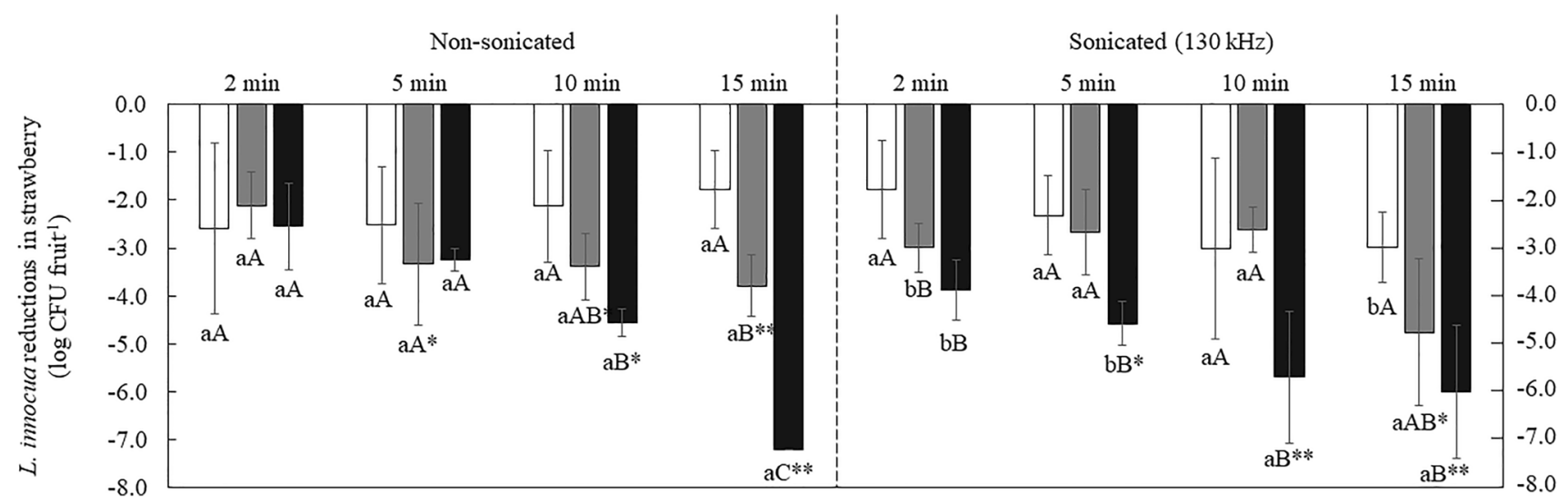

Fig. 2 A Reductions in artificially inoculated Listeria innocua in strawberry with or without sonication $(130 \mathrm{kHz})$, at $20{ }^{\circ} \mathrm{C}$ (grey), $50{ }^{\circ} \mathrm{C}$ (dark grey), or $55{ }^{\circ} \mathrm{C}$ (black). Values are the mean \pm standard deviation $(n=3)$. Lowercase letters show statistical differences $(p<0.05)$ between sonication (non-sonicated or sonicated) within the same temperature and treatment time, and capital letters show statis- tical differences between temperatures $\left(20,50\right.$, or $\left.55^{\circ} \mathrm{C}\right)$ within the same sonication condition and treatment time. Asterisk mark represents sampling times at which the population significantly decreased $(p<0.05)$ in comparison to the previous times in the same combination sonication-temperature, according to Tukey's HSD test 


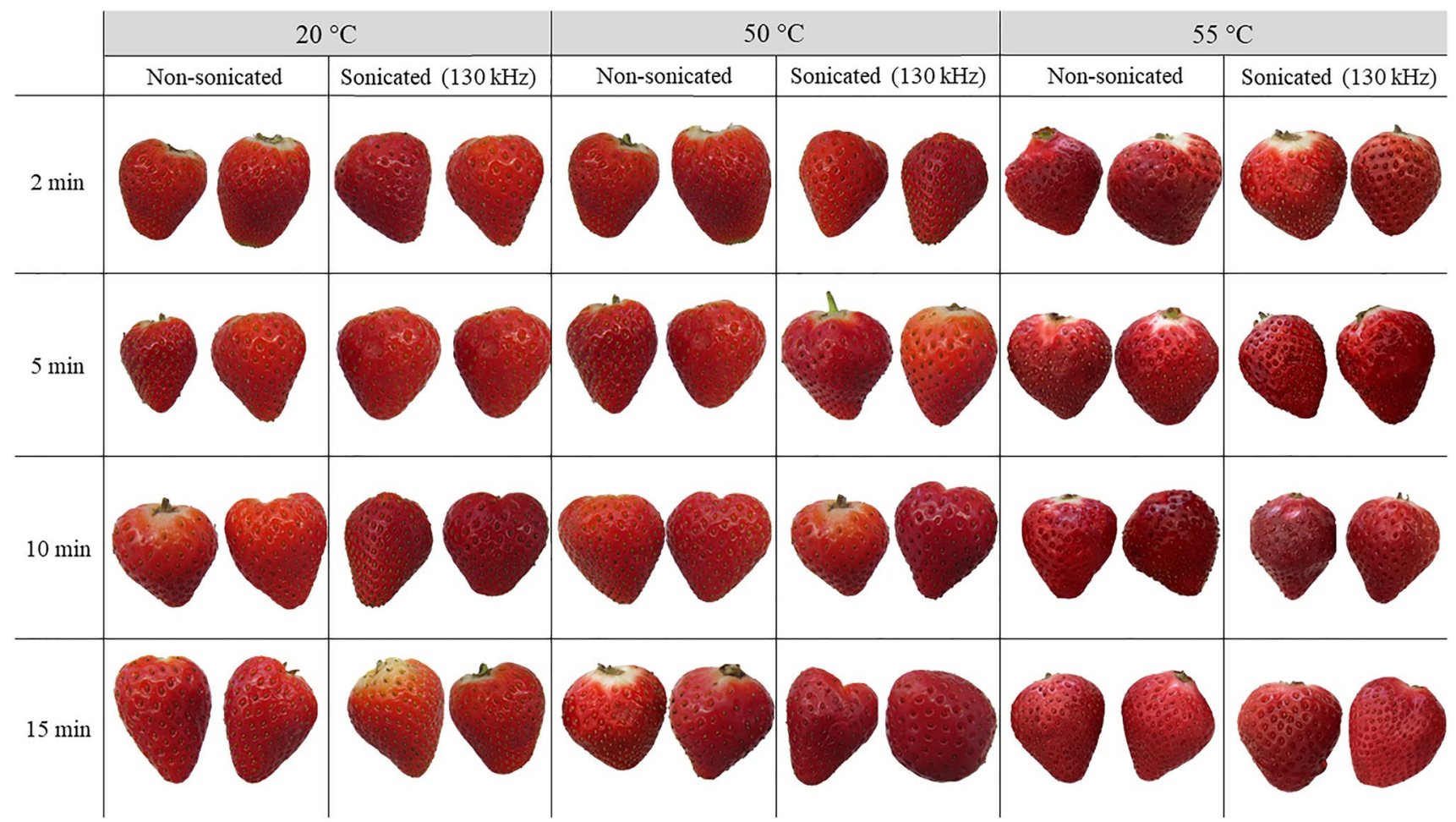

Fig. 3 Strawberries after the treatments (non-sonicated and sonicated at $130 \mathrm{kHz}$ ) at different temperatures $\left(20,50,55^{\circ} \mathrm{C}\right)$ for $2-15 \mathrm{~min}$

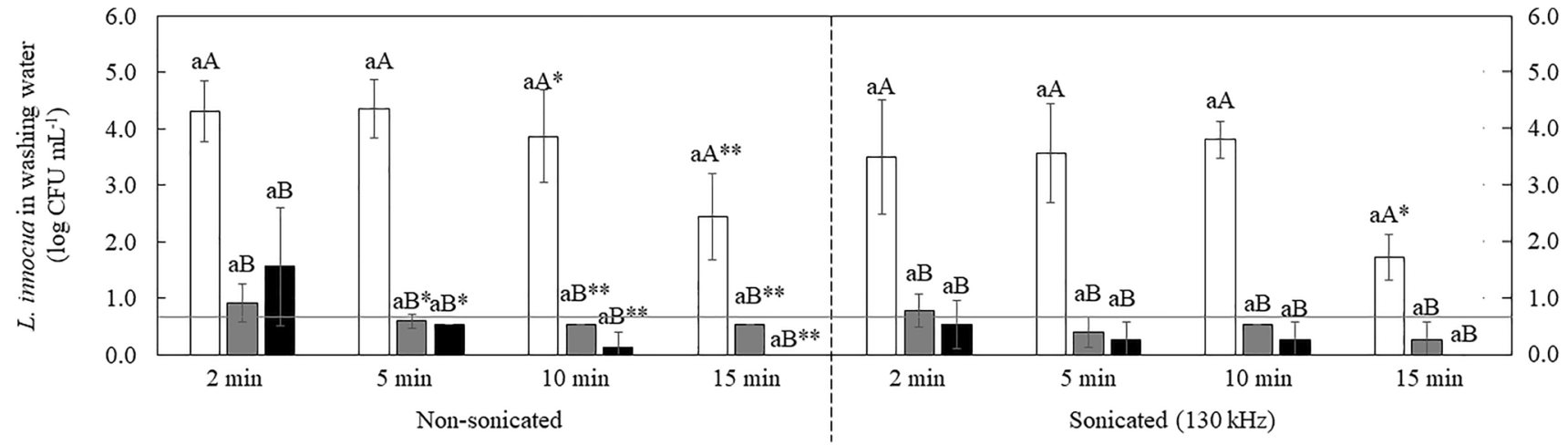

Fig. 4 Listeria innocua populations remaining in water after the treatments with or without sonication $(130 \mathrm{kHz})$, at $20{ }^{\circ} \mathrm{C}$ (grey), $50{ }^{\circ} \mathrm{C}$ (dark grey), or $55^{\circ} \mathrm{C}$ (black). Values are the mean \pm standard deviation $(n=3)$. Lowercase letters show statistical differences $(p<0.05)$ between sonication (non-sonicated or sonicated) within the same temperature and treatment time, and capital letters show statisti-

found at 50 and $55{ }^{\circ} \mathrm{C}$ when compared to those at $20{ }^{\circ} \mathrm{C}$, with most of counts below the detection limit. Contrarily, no differences in the population of $L$. innocua in the wash water were observed between 50 and $55^{\circ} \mathrm{C}$, which ranged between 1.6 after 2 min to below the detection limit after 15 min, regardless the sonication treatment.

Based on the results of efficacy in reduction of $L$. innocua and the visual aspect of the samples after treatment cal differences between temperatures $\left(20,50\right.$, or $\left.55^{\circ} \mathrm{C}\right)$ within the same sonication condition and treatment time. Asterisk mark represents sampling times at which the population significantly decreased $(p<0.05)$ in comparison to the previous times in the same combination sonication-temperature, according to Tukey's HSD test. Grey line represents the detection limit line represents

(Figure 3), selected treatments were $50{ }^{\circ} \mathrm{C}$ for 5 and $10 \mathrm{~min}$, and $55{ }^{\circ} \mathrm{C}$ for $5 \mathrm{~min}$, sonicated at $130 \mathrm{kHz}$ or not. A $20^{\circ} \mathrm{C}$ non-sonicated treatment for 5 and $10 \mathrm{~min}$ was used as a control. The treatments at $55^{\circ} \mathrm{C}$ for 10 and $15 \mathrm{~min}$ and 50 ${ }^{\circ} \mathrm{C}$ for $15 \mathrm{~min}$ were rejected due to the loss of quality, which was visually assessed and showed that strawberries acquired a cooked aspect, presented exudation and overcame a loss of firmness (Supplementary Figure). 


\section{Effect of the selected combinations of temperature and sonication on strawberry quality parameters}

\section{Epiphytic microbiota}

The initial microbial load of the strawberries was $4.6 \pm 0.5$ and $3.5 \pm 0.1 \log \mathrm{CFU} \mathrm{g}{ }^{-1}$ for total aerobic mesophilic (TAM) and yeasts and molds (Y\&M), respectively (Table 1). Washing of strawberries in water at $20{ }^{\circ} \mathrm{C}$ did not cause a significant reduction in both populations, regardless the sonication or the treatment time. Besides, 5 min treatment at 50 or $55^{\circ} \mathrm{C}$ revealed no significant changes in TAM population of non-sonicated strawberries. The other treatments carried out at the mild temperatures (including non-sonicated for $10 \mathrm{~min}$ at $50^{\circ} \mathrm{C}$, sonicated for 5 or $10 \mathrm{~min}$ at $50^{\circ} \mathrm{C}$, and sonicated for $5 \mathrm{~min}$ at $55^{\circ} \mathrm{C}$ ) resulted in the decrease in TAM populations, which achieved values averaging $2.6 \pm 0.2$ $\log$ CFU g ${ }^{-1}$. Surprisingly, TAM reductions in non-sonicated samples were higher $(4.2 \pm 0.1 \log$ reductions $)$ than they were in sonicated strawberries at the same temperature $(2.6 \pm 0.7 \log$ reductions $)$. Regarding $\mathrm{Y} \& \mathrm{M}$, counts in strawberries immersed at $20^{\circ} \mathrm{C}$ for 5 or $10 \mathrm{~min}$ did not show significant differences compared to untreated samples. At 50 and $55^{\circ} \mathrm{C}$, and regardless of the time or sonication, $\mathrm{Y} \& \mathrm{M}$ counts decreased significantly to $1.6 \pm 0.2 \log \mathrm{CFU} \mathrm{g}{ }^{-1}$.

\section{Firmness and color}

Strawberry firmness prior to any treatment was $41.0 \pm 8.2$ and $3.3 \pm 0.6 \mathrm{~N}$ tested by compression and penetration tests, respectively (Table 2). Sonication was not a significant factor influencing texture. Although firmness of the fruits after treatments seemed to decrease, the statistical analysis revealed no significant differences between them when firmness was measured by compression test. With penetration test, only samples sonicated at $50{ }^{\circ} \mathrm{C}$ for $5 \mathrm{~min}$ and non-sonicated at $55^{\circ} \mathrm{C}$ for $5 \mathrm{~min}$ showed significantly different values
Table 1 Total aerobic mesophilic (TAM) and yeasts and moulds (Y\&M) in strawberries before and after the treatments

\begin{tabular}{|c|c|c|c|c|}
\hline & & & \multicolumn{2}{|l|}{ Epiphytic microbiota } \\
\hline & & & TAM $\left(\log \mathrm{CFU}^{-1}\right)$ & $\mathrm{Y} \& \mathrm{M}\left(\log \mathrm{CFU}^{-1}\right)$ \\
\hline \multicolumn{3}{|l|}{ Untreated } & $4.6 \pm 0.5^{\mathrm{a}}$ & $3.5 \pm 0.1^{\mathrm{a}}$ \\
\hline \multirow[t]{2}{*}{$20^{\circ} \mathrm{C}$} & \multirow[t]{2}{*}{ Non-sonicated } & $5 \mathrm{~min}$ & $4.6 \pm 0.7^{\mathrm{a}}$ & $3.6 \pm 0.2^{\mathrm{a}}$ \\
\hline & & $10 \mathrm{~min}$ & $4.3 \pm 0.5^{\mathrm{ab}}$ & $3.3 \pm 0.1^{\mathrm{a}}$ \\
\hline \multirow[t]{4}{*}{$50^{\circ} \mathrm{C}$} & \multirow[t]{2}{*}{ Non-sonicated } & $5 \mathrm{~min}$ & $3.9 \pm 0.6^{\mathrm{abcd}}$ & $1.8 \pm 0.5^{\mathrm{b}}$ \\
\hline & & $10 \mathrm{~min}$ & $2.5 \pm 0.5^{\mathrm{de}}$ & $1.6 \pm 0.3^{\mathrm{b}}$ \\
\hline & \multirow[t]{2}{*}{ Sonicated } & $5 \min$ & $2.3 \pm 0.6^{\mathrm{e}}$ & $1.7 \pm 0.1^{\mathrm{b}}$ \\
\hline & & $10 \min$ & $2.8 \pm 0.7^{\text {bcde }}$ & $1.4 \pm 0.1^{\mathrm{b}}$ \\
\hline \multirow[t]{2}{*}{$55^{\circ} \mathrm{C}$} & Non-sonicated & $5 \mathrm{~min}$ & $4.2 \pm 0.1^{\mathrm{ab}}$ & $1.5 \pm 0.2^{\mathrm{b}}$ \\
\hline & Sonicated & $5 \min$ & $2.6 \pm 0.7^{\text {cde }}$ & $1.4 \pm 0.1^{\mathrm{b}}$ \\
\hline
\end{tabular}

Values are the mean of three reps \pm standard deviation. Different letters show statistically significant differences $(p<0.05)$ between treatments (Tukey's test)

Table 2 Firmness assayed by compression and puncture tests and color expressed as CIE Lab coordinates of strawberries before and after the treatments

\begin{tabular}{|c|c|c|c|c|c|c|c|}
\hline & & & \multicolumn{2}{|l|}{ Firmness } & \multicolumn{3}{|l|}{ Color } \\
\hline & & & Compression $(N)$ & Puncture $(N)$ & $\mathrm{L}^{*}$ & $a^{*}$ & $b^{*}$ \\
\hline \multirow{3}{*}{$\begin{array}{l}\text { Untreated } \\
20^{\circ} \mathrm{C}\end{array}$} & \multirow{3}{*}{ Non-sonicated } & & $41.0 \pm 8.2^{\mathrm{a}}$ & $3.3 \pm 0.6^{\mathrm{a}}$ & $42.3 \pm 2.7^{\mathrm{a}}$ & $33.4 \pm 1.3^{\mathrm{ab}}$ & $30.4 \pm 3.9^{\mathrm{ab}}$ \\
\hline & & $5 \mathrm{~min}$ & $43.5 \pm 1.1^{\mathrm{a}}$ & $2.9 \pm 0.2^{\mathrm{ab}}$ & $41.1 \pm 0.5^{\mathrm{a}}$ & $35.0 \pm 0.3^{\mathrm{a}}$ & $31.4 \pm 1.3^{\mathrm{a}}$ \\
\hline & & $10 \min$ & $34.0 \pm 3.2^{\mathrm{a}}$ & $2.1 \pm 0.1^{\mathrm{abc}}$ & $39.3 \pm 0.8^{\mathrm{a}}$ & $34.7 \pm 0.2^{\mathrm{a}}$ & $28.5 \pm 0.7^{\mathrm{ab}}$ \\
\hline \multirow[t]{4}{*}{$50{ }^{\circ} \mathrm{C}$} & \multirow[t]{2}{*}{ Non-sonicated } & $5 \mathrm{~min}$ & $34.3 \pm 6.0^{\mathrm{a}}$ & $2.5 \pm 0.3^{\mathrm{abc}}$ & $41.5 \pm 2.4^{\mathrm{a}}$ & $32.5 \pm 0.5^{\mathrm{b}}$ & $27.9 \pm 3.3^{\mathrm{ab}}$ \\
\hline & & $10 \min$ & $37.2 \pm 7.2^{\mathrm{a}}$ & $2.2 \pm 0.6^{\mathrm{abc}}$ & $40.4 \pm 1.6^{\mathrm{a}}$ & $32.1 \pm 0.5^{\mathrm{b}}$ & $26.6 \pm 2.1^{\mathrm{ab}}$ \\
\hline & \multirow[t]{2}{*}{ Sonicated } & $5 \mathrm{~min}$ & $32.6 \pm 6.5^{\mathrm{a}}$ & $1.9 \pm 0.1^{\mathrm{c}}$ & $39.9 \pm 2.0^{\mathrm{a}}$ & $32.0 \pm 0.5^{\mathrm{b}}$ & $24.3 \pm 1.1^{\mathrm{b}}$ \\
\hline & & $10 \mathrm{~min}$ & $29.7 \pm 4.3^{\mathrm{a}}$ & $2.2 \pm 0.2^{\mathrm{abc}}$ & $41.0 \pm 0.9^{\mathrm{a}}$ & $30.2 \pm 0.7^{\mathrm{c}}$ & $23.7 \pm 1.3^{\mathrm{b}}$ \\
\hline \multirow[t]{2}{*}{$55^{\circ} \mathrm{C}$} & Non-sonicated & $5 \mathrm{~min}$ & $29.3 \pm 4.7^{\mathrm{a}}$ & $2.0 \pm 0.2^{\mathrm{bc}}$ & $37.9 \pm 1.0^{\mathrm{a}}$ & $31.7 \pm 0.7^{\mathrm{b}}$ & $24.1 \pm 0.8^{\mathrm{b}}$ \\
\hline & Sonicated & $5 \mathrm{~min}$ & $32.6 \pm 6.4^{\mathrm{a}}$ & $2.3 \pm 0.4^{\mathrm{abc}}$ & $40.1 \pm 0.4^{\mathrm{a}}$ & $31.6 \pm 0.5^{\mathrm{bc}}$ & $24.7 \pm 0.4^{\mathrm{b}}$ \\
\hline
\end{tabular}

Values are the mean of 3 reps \pm standard deviation. Different letters show statistically significant differences $(p<0.05)$ between treatments $($ Tukey's test) 
from the samples untreated, being $1.9 \pm 0.1$ and $2.0 \pm 0.2 \mathrm{~N}$, respectively.

Strawberry color before treatments expressed as CIE-Lab coordinates was $42.3 \pm 2.7 \mathrm{~L}^{*}, 33.4 \pm 1.3 \mathrm{a}^{*}$, and $30.4 \pm 3.9$ b* (Table 2). After treatments, luminosity expressed by the coordinate $\mathrm{L}^{*}$, did not change significantly. Also, sonication was not a significant factor influencing color. However, at higher temperatures and longer times, lower $a^{*}$ and $b^{*}$ values were observed, implying a change in red: from orangey to more purplish at the end. For instance, sonicated samples at $50{ }^{\circ} \mathrm{C}$ for $10 \mathrm{~min}$ presented $30.2 \pm 0.7 \mathrm{a}^{*}$ and $23.7 \pm 1.3 \mathrm{~b}^{*}$ values, and sonicated samples at $55^{\circ} \mathrm{C}$ for 10 min presented $31.6 \pm 0.5 \mathrm{a}^{*}$ and $24.7 \pm 0.4 \mathrm{~b}^{*}$ values.

\section{Biochemical analyses}

The antioxidant capacity of the strawberries used in this study was measured by DPPH. and FRAP methods, whose values at the beginning of the study were $1.06 \pm 0.12$ and $1.03 \pm 0.10 \mathrm{~g} \mathrm{~kg}^{-1}$, respectively (Table 3). DPPH. value was maintained after treatments regardless the temperature, the sonication or the time, and averaged $1.01 \pm 0.09 \mathrm{~g} \mathrm{~kg}^{-1}$. Except for non-sonicated strawberries treated at $55^{\circ} \mathrm{C}$ for $5 \mathrm{~min}$, whose FRAP value was $1.31 \pm 0.10 \mathrm{~g} \mathrm{~kg}^{-1}$, the other samples did not significantly differ from the control.

The TPC and TAC values of untreated strawberries were $0.95 \pm 0.13 \mathrm{~g} \mathrm{~kg}^{-1}$ and $0.024 \pm 0.001 \mathrm{~g} \mathrm{~kg}^{-1}$, respectively (Table 3). Thermosonication was not detrimental for nutritional quality of the product. In this regard, TPC values of the treated samples (which ranged from $0.88 \pm 0.02 \mathrm{~g} \mathrm{~kg}^{-1}$ in non-sonicated strawberries washed for $10 \mathrm{~min}$ at $20^{\circ} \mathrm{C}$ to $1.15 \pm 0.01 \mathrm{~g} \mathrm{~kg}^{-1}$ in non-sonicated strawberries treated at $55^{\circ} \mathrm{C}$ for $5 \mathrm{~min}$ ) were not statistically different from that of treatments. Similarly, TAC values after thermosonication were also not statistically different from the untreated and ranged from $0.017 \pm 0.003 \mathrm{~g} \mathrm{~kg}^{-1}$ in non-sonicated strawberries washed for $5 \mathrm{~min}$ to $0.029 \pm 0.004 \mathrm{~g} \mathrm{~kg}^{-1}$ in sonicated samples treated at $50{ }^{\circ} \mathrm{C}$ for $5 \mathrm{~min}$ and in non-sonicated samples at $55^{\circ} \mathrm{C}$ for $5 \mathrm{~min}$.

\section{Discussion}

The effects of combination of mild temperatures with sonication against $L$. innocua both in vitro and on fresh strawberries were investigated in this work, as several studies have indicated that sonication alone is not successful to inactivate L. monocytogenes sufficiently unless combined with other techniques, including mild temperatures $\left(>60^{\circ} \mathrm{C}\right)$ [21].

In the present study, mild temperatures of 50 and $55^{\circ} \mathrm{C}$ were selected to maintain quality parameters in a fruit that is sensible to heat due to the lack of peel. At in vitro conditions, only the treatment at $55^{\circ} \mathrm{C}$ combined with ultrasound at 35 or $130 \mathrm{kHz}$ over $10 \mathrm{~min}$ was effective to significantly reduce $L$. innocua population. Generally, higher temperatures at same acoustic intensity achieve relatively higher microbial reductions by increased cavitation [22]. When ultrasound was combined with $50^{\circ} \mathrm{C}$ treatment for $15 \mathrm{~min}$, only a $0.3 \log$ reduction was observed. Possibly, the selected combination for ultrasound and temperature parameters was not enough to inactivate $L$. innocua populations, and a higher time would have been needed to see a significant effect. At $55^{\circ} \mathrm{C}, 130 \mathrm{kHz}$ showed higher efficacy than $35 \mathrm{kHz}$. Typically, a higher frequency increases the intensity of cavitation,

Table 3 Antioxidant capacity by DPPH or FRAP methods, total phenolic content (TPC) and total anthocyanin content (TAC), of strawberries before and after the treatments

\begin{tabular}{|c|c|c|c|c|c|c|}
\hline & & & \multicolumn{2}{|l|}{ Antioxidant capacity } & \multicolumn{2}{|l|}{ Phenolic content } \\
\hline & & & DPPH.(AAE, $\mathrm{g} \mathrm{kg}^{-1}$ ) & FRAP (AAE, $\left.\mathrm{g} \mathrm{kg}^{-1}\right)$ & TPC (GAE, $\left.\mathrm{g} \mathrm{kg}^{-1}\right)$ & $\begin{array}{l}\text { TAC (cianidine- } \\
\text { 3-glucosyde, } \mathrm{g} \\
\mathrm{kg}^{-1}\end{array}$ \\
\hline \multirow{3}{*}{$\begin{array}{c}\text { Untreated } \\
20{ }^{\circ} \mathrm{C}\end{array}$} & & & $1.06 \pm 0.12^{\mathrm{a}}$ & $1.03 \pm 0.10^{\mathrm{b}}$ & $0.95 \pm 0.13^{\mathrm{ab}}$ & $0.024 \pm 0.001^{\mathrm{ab}}$ \\
\hline & Non-sonicated & $5 \min$ & $1.09 \pm 0.06^{\mathrm{a}}$ & $1.20 \pm 0.11^{\mathrm{ab}}$ & $1.04 \pm 0.05^{\mathrm{ab}}$ & $0.017 \pm 0.003^{\mathrm{b}}$ \\
\hline & & $10 \mathrm{~min}$ & $0.93 \pm 0.02^{\mathrm{a}}$ & $1.05 \pm 0.04^{\mathrm{b}}$ & $0.88 \pm 0.02^{\mathrm{b}}$ & $0.025 \pm 0.002^{\mathrm{ab}}$ \\
\hline \multirow[t]{4}{*}{$50^{\circ} \mathrm{C}$} & Non-sonicated & $5 \mathrm{~min}$ & $0.98 \pm 0.14^{\mathrm{a}}$ & $1.28 \pm 0.06^{\mathrm{ab}}$ & $1.15 \pm 0.01^{\mathrm{a}}$ & $0.023 \pm 0.005^{\mathrm{ab}}$ \\
\hline & & $10 \mathrm{~min}$ & $1.02 \pm 0.05^{\mathrm{a}}$ & $1.21 \pm 0.10^{\mathrm{ab}}$ & $0.99 \pm 0.03^{\mathrm{ab}}$ & $0.024 \pm 0.003^{\mathrm{ab}}$ \\
\hline & Sonicated & $5 \min$ & $0.96 \pm 0.04^{\mathrm{a}}$ & $1.12 \pm 0.05^{\mathrm{ab}}$ & $0.96 \pm 0.06^{\mathrm{ab}}$ & $0.029 \pm 0.004^{\mathrm{a}}$ \\
\hline & & $10 \mathrm{~min}$ & $0.97 \pm 0.51^{\mathrm{a}}$ & $1.13 \pm 0.07^{\mathrm{ab}}$ & $0.96 \pm 0.04^{\mathrm{ab}}$ & $0.025 \pm 0.002^{\mathrm{a}}$ \\
\hline \multirow[t]{2}{*}{$55^{\circ} \mathrm{C}$} & Non-sonicated & $5 \min$ & $1.15 \pm 0.08^{\mathrm{a}}$ & $1.31 \pm 0.10^{\mathrm{a}}$ & $1.12 \pm 0.08^{\mathrm{a}}$ & $0.029 \pm 0.001^{\mathrm{a}}$ \\
\hline & Sonicated & $5 \min$ & $1.02 \pm 0.05^{\mathrm{a}}$ & $1.14 \pm 0.05^{\mathrm{ab}}$ & $0.97 \pm 0.09^{\mathrm{ab}}$ & $0.023 \pm 0.001^{\mathrm{ab}}$ \\
\hline
\end{tabular}

Values are the mean of three reps \pm standard deviation. Different letters show statistically significant differences $(p<0.05)$ between treatments (Tukey's test)

$A A E$ ascorbic acid equivalents; GAE gallic acid equivalents 
leading to a higher ratio of cell death [22]. However, no differences between both frequencies were observed when no sonication was applied. In contrast, Franco-Vega et al. [10] found that the treatment time to achieve the same reduction in L. monocytogenes counts in tryptic soy broth $\mathrm{pH} 6$ was halved with thermosonication at $55-65^{\circ} \mathrm{C}$ when compared with thermal inactivation at the same temperatures alone. Similarly, Muñoz et al. [21] reported a significant decrease (1.1 log units) in L. innocua counts after sonicating at $20 \mathrm{kHz}$ a buffered solution containing this microorganism for $2 \mathrm{~min}$. Indeed, efficacy of ultrasound not only depends on the temperature to which it is combined, but on a number of factors, including wave frequency, power and treatment time [22]. For this, and as the observed in vitro reductions of L. innocua at $55{ }^{\circ} \mathrm{C}$ were higher when $130 \mathrm{kHz}$ were used (achieving $4.0 \mathrm{log}$ reductions compared to the $2.4 \mathrm{log}$ reductions observed at $35 \mathrm{kHz}$ ), this frequency was the one selected for further investigations in this study.

To apply this technology in vivo, i.e. to a fruit matrix for its processing, and according to Patras, Brunton, Donnell, and Tiwari [23], it is not possible to predict the effect of a thermal treatment on retention of bioactive compounds, so it becomes necessary to evaluate each case individually. Heat processing is usually used in the fruit processing industry for liquids and fluids, such as juices, nectars, purées and jams. Though, as Lafarga et al. [22] recently reviewed, mild heat treatments are more appropriate for fresh and minimally processed strawberries, due to the changes that high temperatures could cause to the fruit. For this, in the present study, sonication was suggested as a technology to be combined with mild temperatures for sanitization of strawberries, assuming there would be an additive effect that could help to decrease the temperatures and the time needed to achieve the same results that could be obtained with a more aggressive treatment. For this, a screening test using the $L$. innocua counts remaining in strawberry and in wash water after treatments as a criterion was employed to select the best combinations 'Ultrasound' $\times$ 'Temperature' $\times$ 'Time'. In this regard, when studying the effect of sonication at $20^{\circ} \mathrm{C}$, it was revealed that sonication was able to significantly reduce L. innocua counts in strawberries more than in non-sonicated samples. This could be attributed to the detachment of the microorganisms from the surface of the strawberry to the water induced by cavitation processes, as bubbles generated collapse near the fruit surface and may separate the microorganism from it [4]. Indeed, ultrasound capacity to remove bacterial cells from the surface has been recognized, as it influences the flagella and fimbriae of the bacteria, as well as their attachment ability [26]. However, some studies failed in significantly decontaminate food products with only the application of sonication. For instance, 30 or 45 min sonication times were needed to significantly reduce E. coli, Staphylococcus aureus and L. innocua populations in strawberries and lettuce, respectively [27]. Also, Anese, Maifreni, Bot, Bartolomeoli, and Nicoli [26] reported that L. monocytogenes count in waste-water of fresh-cut lettuce wash was reduced by $5 \log$ after continuous sonication for $5 \mathrm{~min}$, but it should be noted that the temperature at the end of the study reached $60{ }^{\circ} \mathrm{C}$, so the effect was the result of the combination of mild temperature with ultrasound. Our study also demonstrated that higher temperatures and times (50 and $55^{\circ} \mathrm{C}$ for more than $10 \mathrm{~min}$ ) exert a significant effect in decreasing $L$. innocua populations both in strawberry and wash water (where a population lower than the detection limit was reached). However, one of the problems of washing strawberries is that remaining moisture in the fruit can make them more exposed to fungal growth [29]. For this and for the timing in fruit processing industries, these washing times are often excessive for fresh and fresh-cut fruits and vegetables. Furthermore, sometimes the additional time is not related with an additional and significant pathogenic reduction, as other authors have reported that ultrasound treatment for 10 min can achieve the maximal removal of attached bacteria from fruits and vegetable surfaces without significant damage to the fresh produce quality [30]. According to them, exposure to ultrasound treatment maximum 10 min is potentially adequate for decontamination of fresh produce, while minimizing the impact on the nutritional and organoleptic properties of fresh produce. Huang, Wrenn, Tikekar, and Nitin [29] also reported that treatment times longer than 10 min did not significantly enhance the removal of E. coli, L. innocua, and Pseudomonas fluorescens from the inoculated lettuce leaf samples sonicated at $20{ }^{\circ} \mathrm{C}$ with a frequency of $45 \mathrm{kHz}$. Reductions in such $L$. innocua populations were $2.2 \pm 0.1 \log \mathrm{CFU} \mathrm{cm}{ }^{-2}$. In the present study, and at $20^{\circ} \mathrm{C}$, more than 15 min were needed to reach levels of $2.1 \pm 0.5 \log \mathrm{CFU} \mathrm{mL} \mathrm{m}^{-1}$ in wash water, which makes evident the need to combine ultrasounds with mild temperatures. It must be noted that a higher efficacy against L. innocua was observed when applying sonication with $50{ }^{\circ} \mathrm{C}$ to strawberries rather than what happened in vitro at the same temperature. One possible hypothesis proposed for this behavior is that the higher efficacy of thermosonication treatment on L. innocua on the strawberry may be related to the time spent on its surface: the acidic conditions and the overnight period at $4{ }^{\circ} \mathrm{C}$ after the artificial inoculation may have increased its susceptibility. Despite this, careful use of mild temperatures is always advised, as the main concern of mild thermal processing it that it can sub-lethally injure the bacteria, which in turn, may allow them to recover and grow during storage afterwards.

Based on the effects that different combinations of temperature, sonication and time had on L. innocua populations in treated strawberries, a selection of six treatments was carried out for further experiments involving quality determination. At $50{ }^{\circ} \mathrm{C}$, sonication or no sonication treatments 
for 5 or 10 min were selected, whilst at $55^{\circ} \mathrm{C}$, only $5 \mathrm{~min}$ treatment time was selected, with or without sonication (as longer treatments gave strawberries were deleterious for strawberry quality, as explained in Sect. 3.2). Treatments at $20^{\circ} \mathrm{C}$ were carried out as a reference, to see the effect that sonication or immersion in water for a certain time had on the different parameters evaluated afterwards. Similar to what happened with L. innocua population, treatments performed at $20^{\circ} \mathrm{C}$-regardless sonication- did not have an effect on TAM and Y\&M counts. By this way, ultrasound at $20 \mathrm{kHz}$ frequency and $30-90 \mathrm{~W}$ power for 5 or $10 \mathrm{~min}$ did not result in significant decreases in TAM and Y\&M counts in strawberries when compared to non-treated control [32]. The fact that the TAM and Y\&M reductions did not depend on sonication could be explained by the stronger attachment to the strawberry surface these microorganisms have acquired compared with that of L. innocua; the latter was artificially inoculated the day before the experiment, whilst TAM and Y\&M have accompanied the fruit for a longer time and may have become more attached to it, forming biofilms or internalized in stomata. In this case, temperature was the factor which had significant effect in reducing epiphytic populations in strawberry. Even this strategy has been studied as an alternative to prevent microbial spoilage in fresh and processed strawberry products, sonication alone does not exert a great impact in epiphytic microbiota of these fruits, as reviewed in Lafarga et al. [22]. However, both in the present study and as reviewed in the literature, when combined with mild temperatures, a greater effect was detected regardless the sonication. For instance, and related to temperature, hot water treatment of strawberries $\left(45^{\circ} \mathrm{C}\right.$ for $5 \mathrm{~min}$ ) prevented the incidence of decay during storage at $4{ }^{\circ} \mathrm{C}$ for 9 days and then transferred to $16^{\circ} \mathrm{C}$ for 3 days [33]. In microbial studies, the use of heterogeneous solid matrix such as strawberries is a challenge and could give high variability in the results due to their intrinsic properties and to differences in the indigenous microbiota. Thus, more experiments using a homogeneous model system (e.g., using purée, avoiding unitary differences by creating a homogenate of a pool of fruits) could be useful to deepen in the efficacy of ultrasound in combination with temperature.

The decrease in firmness contributes to fruit susceptibility to decay. Therefore, any treatment able to delay softening is potentially helpful to extend postharvest life of strawberries [33]. Immediately after the treatments in which mild temperatures, combined or not with sonication, were applied, firmness evaluated by compression test was not significantly affected. Variations in this parameter, attributed to the different shapes and widths fruit pieces, could be a reason for the lack of significance. In contrast, when analyzing the results of penetration test, some samples showed differences from the controls. It is believed that the penetration approach is more suitable when different shapes are studied, as it evaluates the force made with the tip of the probe in a smaller area, while compression test uses a larger area in which the contact surface may vary between samples. There is no consensus about the effect of heat and sonication may have on strawberries. For instance, some authors reported that heat-treated fruit remained firmer than control [33], but it should be noted that they applied dry heat instead of immersing strawberries in hot water. Other studies performed with the same immersion method that in the present study, also reported contradictory results: heat treatment in water at $45^{\circ} \mathrm{C}$ for 15 min enhanced firmness in 'Tudla' strawberry fruit [34], while the same treatment affected firmness of 'Pájaro' fruit negatively [35]. The softening of strawberries immediately after some treatments in the present study should be carefully considered if they are for fresh market. However, the suitability of those fruits to be processed as frozen products or sold as an ingredient for other products should be assessed.

Color and appearance are quality attributes that mainly affect whether a fruit product is accepted or rejected; therefore, this is one of the most critical quality attributes [36]. In this study, the color parameters described for untreated strawberries, which are in accordance to that reported in the literature, represent a brilliant red color. However, strawberries acquired a more purplish color after treatments that included mild temperatures. Some authors reported that ultrasound application ( 20 or $33 \mathrm{kHz}$, at $60 \mathrm{~W}$ ) improved color of treated strawberries [37], while others described the changes in color after heat treatment up to $90{ }^{\circ} \mathrm{C}$ for $15 \mathrm{~min}$ as barely visible in strawberry purée [38]. Özsen and Erge [37] reported that $a^{*}$ and $b^{*}$ values decreased in strawberry pulp with higher temperatures: at $60{ }^{\circ} \mathrm{C}$, these parameters had decreased a 13.3 and $9.3 \%$, respectively. In the present study, the variations were 6.0 and $24.4 \%$ for a* and $b^{*}$, respectively. The changes in color of strawberries could be attributed to the variations in anthocyanin content, as these compounds are accountable for it [40].

Values of TPC and TAC of strawberries used for the treatments are in accordance for those already reported in strawberries from the same origin $[19,41]$. In the present study, TAC and TPC values did not overcome major changes after heat treatment with or without sonication. On the contrary, some authors have reported a decrease in anthocyanin content after exposing strawberries or strawberry juice to heat treatments from 60 to $90^{\circ} \mathrm{C}[39,42]$. Also, the TPC and the TAC values, together with tannins and vitamin $C$, are the ones which mainly give the antioxidant properties to strawberries [43]. The absence of major changes in these compounds' contents after treatments could be the reason why antioxidant capacity expressed by DPPH. values was maintained for all the treatments and, excepting for one treatment, also by the FRAP values. Another possible explanation could be that, while some antioxidant molecules are lost 
with heat treatments, formation of new antioxidants could occur during this process [40]. In fact, sonication is likely to alter quality during time; cavitation can produce radicals that can initiate the degradation of the products as well as trigger chain reactions [21]. Sonication could also lead to the breakup of some cell walls of the strawberry, releasing the molecules inside. Moreover, heat treatment could trigger or inactivate phenylalanine ammonia lyase (PAL), an enzyme involved in the biosynthesis of the polyphenol compounds such as flavonoids, phenylpropanoids, and lignin in plants [44]. For this, it should be advisable to perform more investigation including the evolution of quality parameters during time.

\section{Conclusions}

Overall, the present study suggests that, at the tested conditions, sonication played a minor role in reducing $L$. innocua counts, both in vitro (studied in a suspension) and in vivo (in artificially inoculated strawberries) and the main effects of microbial reduction could mainly be attributed to temperature.

Maximum reduction of L. innocua in strawberries was achieved by thermosonication at $130 \mathrm{kHz}$ and $55^{\circ} \mathrm{C}$ for $10 \mathrm{~min}$, accounting for $4.0 \log$ unit reduction. However, this treatment caused a decrease in the freshness appearance of the strawberries that made them inappropriate for the fresh market. However, they could be used for further processing, e.g., for freezing, purées, or as an ingredient for other products. Fortunately, thermosonication at $50{ }^{\circ} \mathrm{C}$ for 5 or $10 \mathrm{~min}$, or at $55^{\circ} \mathrm{C}$ for $5 \mathrm{~min}$ did not cause major changes in strawberry quality and biochemical parameters analyzed, except for a slight darkening and softening observed after the strongest treatments.

This research extends our knowledge of the application of thermosonication for strawberry sanitation. This technique could be a good approach to produce strawberries that accomplish safety and quality standards, but more research is needed to reach its full potentiality.

Supplementary Information The online version contains supplementary material available at https://doi.org/10.1007/s00217-021-03913-9.

Acknowledgements The authors thank the support of L. Abad in the experimental part.

Funding Open Access funding provided thanks to the CRUE-CSIC agreement with Springer Nature. 'Ministerio de Economia, Industria y Competitividad' was the financial support of the project AGL201678086-R and the CERCA Programme of the 'Generalitat de Catalunya' (Spain). I. Nicolau-Lapena is in receipt of a predoctoral grant awarded by the 'Ministerio de Economia, Industria y Competitividad' (grant number BES-2017-079779). Dr. I. Aguilo-Aguayo thanks the National Programme for the Promotion of Talent and Its Employability of the
'Ministerio de Economia, Industria y Competitividad' of the Spanish Government and the European Social Fund for her Postdoctoral Senior Grant 'Ramon y Cajal' (RYC-2016-2019 949).

\section{Declarations}

Conflict of interest The authors declare no conflict of interests.

Compliancewith ethics requirements This study does not contain any studies with human participants or animals.

Data availability Data are available under reasonable request to the corresponding author.

Open Access This article is licensed under a Creative Commons Attribution 4.0 International License, which permits use, sharing, adaptation, distribution and reproduction in any medium or format, as long as you give appropriate credit to the original author(s) and the source, provide a link to the Creative Commons licence, and indicate if changes were made. The images or other third party material in this article are included in the article's Creative Commons licence, unless indicated otherwise in a credit line to the material. If material is not included in the article's Creative Commons licence and your intended use is not permitted by statutory regulation or exceeds the permitted use, you will need to obtain permission directly from the copyright holder. To view a copy of this licence, visit http://creativecommons.org/licenses/by/4.0/.

\section{References}

1. Bevilacqua A, Petruzzi L, Perricone M, Speranza B, Campaniello D, Sinigaglia M et al (2018) Nonthermal technologies for fruit and vegetable juices and beverages: overview and advances. Compr Rev Food Sci Food Saf 17(1):2-62

2. Pérez-Andrés JM, Charoux CMG, Cullen PJ, Tiwari BK (2018) Chemical modifications of lipids and proteins by nonthermal food processing technologies. J Agric Food Chem [Internet] 66(20):5041-5054. https://doi.org/10.1021/acs.jafc.7b06055

3. Leong T, Juliano P, Knoerzer K (2017) Advances in ultrasonic and megasonic processing of foods. Food Eng Rev 9(3):237-256

4. Nicolau-Lapeña I, Lafarga T, Viñas I, Abadias M, Bobo G, Aguiló-Aguayo I (2019) Ultrasound processing alone or in combination with other chemical or physical treatments as a safety and quality preservation strategy of fresh and processed fruits and vegetables: a review. Food Bioprocess Technol 12(9):1452-1471

5. Chandrapala J, Oliver C, Kentish S, Ashokkumar M (2012) Ultrasonics in food processing - Food quality assurance and food safety. Trends Food Sci Technol [Internet] 26(2):88-98. https://doi.org/ 10.1016/j.tifs.2012.01.010

6. Piyasena P, Mohareb E, McKellar RC (2003) Inactivation of microbes using ultrasound: a review. Int J Food Microbiol 87(3):207-216

7. Doyle MP, Erickson MC, Alali W, Cannon J, Deng X, Ortega Y et al (2015) The food industry's current and future role in preventing microbial foodborne illness within the united states. Clin Infect Dis 61(2):252-259

8. Zhu Q, Gooneratne R, Hussain MA (2017) Listeria monocytogenes in fresh produce: outbreaks, prevalence and contamination levels. Foods [Internet]. 6(3):21. http://www.mdpi.com/2304$8158 / 6 / 3 / 21$

9. Swaminathan B, Gerner-Smidt P (2007) The epidemiology of human listeriosis. Microbes Infect 9(10):1236-1243 
10. Franco-Vega A, Ramírez-Corona N, López-Malo A, Palou E (2015) Estimation of Listeria monocytogenes survival during thermo-ultrasonic treatments in non-isothermal conditions: effect of ultrasound on temperature and survival profiles. Food Microbiol 52:124-130

11. Bermúdez-Aguirre D, Corradini MG, Mawson R, Barbosa-Cánovas GV (2009) Modeling the inactivation of Listeria innocua in raw whole milk treated under thermo-sonication. Innov Food Sci Emerg Technol [Internet] 10(2):172-178. https://doi.org/10. 1016/j.ifset.2008.11.005

12. Anaya-Esparza LM, Velázquez-Estrada RM, Roig AX, GarcíaGalindo HS, Sayago-Ayerdi SG, Montalvo-González E (2017) Thermosonication: an alternative processing for fruit and vegetable juices. Trends Food Sci Technol [Internet] 61:26-37. https:// doi.org/10.1016/j.tifs.2016.11.020

13. Flessa S, Lusk DM, Harris LJ (2005) Survival of Listeria monocytogenes on fresh and frozen strawberries. Int J Food Microbiol 101(3):255-262

14. Penteado AL, Leita MFF (2004) Growth of Listeria monocytogenes in melon, watermelon and papaya pulps. Int J Food Microbiol 92:89-94

15. Honjoh K, Iwaizako Y, Lin Y, Kijima N, Miyamoto T (2016) Possibilities for contamination of tomato fruit by Listeria monocytogenes during cultivation. Food Sci Technol Res 22(3):394-357

16. Caggia C, Scifo GO, Restuccia C, Randazzo CL (2009) Growth of acid-adapted Listeria monocytogenes in orange juice and in minimally processed orange slices. Food Control 20:59-66

17. Francis GA, O'Beirne DO (1997) Effects of gas atmosphere, antimicrobial dip and temperature on the fate of Listeria innocua and Listeria monocytogenes on minimally processed lettuce. Int J Food Sci Technol 32(2):141-151

18. Pyatkovskyy T, Shinkaryk M, Mohamed H, Yousef A, Sastry S (2018) Effects of combined high pressure (HPP), pulsed electric fields (PEF) and sonication treatments on inactivation of Listeria innocua. J Food Eng 233:49-56

19. Nicolau-Lapeña I, Abadias M, Bobo G, Aguiló-Aguayo I, Lafarga T, Viñas I (2019) Strawberry sanitization by peracetic acid washing and its effect on fruit quality. Food Microbiol [Internet] 83:159-166. https://linkinghub.elsevier.com/retrieve/pii/S0740 002018312309

20. Meyers K, Watkins C, Pritts M, Liu R (2003) Antioxidant and antiproliferative activities of strawberries. J Agric Food Chem 51:6887-6892

21. Bahrami A, Moaddabdoost Baboli Z, Schimmel K, Jafari SM, Williams L (2020) Efficiency of novel processing technologies for the control of Listeria monocytogenes in food products. Trends Food Sci Technol [Internet] 96:61-78. https://doi.org/10.1016/j. tifs.2019.12.009

22. Alzamora SM, Guerrero SN, Schenk M, Rafellini S, López-Malo A (2011) Inactivation of microorganisms. In: Feng H, BarbosaCanovas G, Weiss J (eds) Ultrasound technologies for food and bioprocessing, 1st edn. Springer, pp 321-343

23. Muñoz A, Palgan I, Noci F, Cronin DA, Morgan DJ, Whyte $\mathrm{P}$ et al (2012) Combinations of selected non-thermal technologies and antimicrobials for microbial inactivation in a buffer system. Food Res Int [Internet] 47(1):100-105. https://doi.org/10.1016/j.foodr es.2012.02.001

24. Lafarga T, Colás-Medà P, Abadías M, Aguiló-aguayo I, Bobo G (2019) Strategies to reduce microbial risk and improve quality of fresh and processed strawberries: a review. Innov Food Sci Emerg Technol [Internet]. 52:197-212. https://doi.org/10.1016/j. ifset.2018.12.012

25. Patras A, Brunton NP, Donnell CO, Tiwari BK (2010) Effect of thermal processing on anthocyanin stability in foods; mechanisms and kinetics of degradation. Trends Food Sci Technol [Internet] 21(1):3-11. https://doi.org/10.1016/j.tifs.2009.07.004
26. Tan MSF, Rahman S, Dykes GA (2017) Sonication reduces the attachment of Salmonella Tyhphimurium ATCC 14028 cells to bacterial cellulose-based plant cell wall models and cut plant material. Food Microbiol 62:62-67

27. Birmpa A, Sfika V, Vantakaris A (2013) Ultraviolet light and ultrasound as non-thermal treatments for the reduction of microorganisms in fresh ready-to-eat foods. Int J Food Microbiol 167(1):96-102

28. Anese M, Maifreni M, Bot F, Bartolomeoli I, Nicoli MC (2015) Power ultrasound decontamination of wastewater from fresh-cut lettuce washing for potential water recycling. Innov Food Sci Emerg Technol [Internet] 32:121-126. https://doi.org/10.1016/j. ifset.2015.09.005

29. Baicu AA, Popa ME (2018) Trends in prolonging the post-harvest life of strawberries - a review. Ann Univ Dunarea Jos Galati Fascicle VI Food Technol 42(1):9-16

30. Bilek SE, Turantaş F (2013) Decontamination efficiency of high power ultrasound in the fruit and vegetable industry, a review. Int J Food Microbiol 166(1):155-162

31. Huang K, Wrenn S, Tikekar R, Nitin N (2017) Efficacy of decontamination and a reduced risk of cross-contamination during ultrasound-assisted washing of fresh produce. J Food Eng 224:95-104

32. Aday MS, Temizkan R, Büyükcan MB, Caner C (2013) An innovative technique for extending shelf life of strawberry: ultrasound. LWT - Food Sci Technol [Internet] 52(2):93-101. https://doi.org/ 10.1016/j.lwt.2012.09.013

33. Vicente AR, Mart1 GA, Civello PM (2002) Quality of heat-treated strawberry fruit during refrigerated storage. Postharvest Biol Technol 25:59-71

34. García JM, Aguilera C, Albi MA (1995) Postharvest heat treatment on spanish strawberry (Fragaria $\times$ ananassa $\mathrm{Cv}$. Tudla). J Agric Food Chem 43(6):1489-1492

35. Lara I, García P, Vendrell M (2006) Post-harvest heat treatments modify cell wall composition of strawberry (Fragaria $\times$ ananassa Duch.) fruit. Sci Hortic (Amsterdam) 109(1):48-53

36. Barrett DM, Beaulieu JC, Shewfelt R (2010) Color, flavor, texture, and nutritional quality of fresh-cut fruits and vegetables: Desirable levels, instrumental and sensory measurement, and the effects of processing. Crit Rev Food Sci Nutr 50(5):369-389

37. Gani AA, Baba WN, Ahmad M, Shah U, Khan AA, Wani IA et al (2016) Effect of ultrasound treatment on physico-chemical, nutraceutical and microbial quality of strawberry. LWT Food Sci Technol [Internet] 66:496-502. https://doi.org/10.1016/j.lwt.2015. 10.067

38. Marszałek K, Mitek M, Skąpska S (2015) The effect of thermal pasteurization and high pressure processing at cold and mild temperatures on the chemical composition, microbial and enzyme activity in strawberry purée. Innov Food Sci Emerg Technol 27:48-56

39. Özsen D, Erge HS (2012) Degradation kinetics of bioactive compounds and change in the antioxidant activity of wild strawberry (Fragaria vesca) pulp during heating. Food Bioprocess Technol 6(9):2261-2267

40. Alvarez-Suarez JM, Mazzoni L, Forbes-Hernandez TY, Gasparrini M, Sabbadini S, Giampieri F (2014) The effects of pre-harvest and post-harvest factors on the nutritional quality of strawberry fruits: a review. J Berry Res 4(1):1-10

41. Nicolau-Lapeña I, Abadias M, Viñas I, Bobo G, Lafarga T, Ribasagustí A et al (2020) Water UV-C treatment alone or in combination with peracetic acid: a technology to maintain safety and quality of strawberries. Int J Food Microbiol [Internet] 335:108887. https://doi.org/10.1016/j.ijfoodmicro.2020.108887

42. Odriozola-Serrano I, Soliva-Fortuny R, Martín-Belloso O (2009) Influence of storage temperature on the kinetics of the changes in anthocyanins, vitamin $\mathrm{C}$, and antioxidant capacity in fresh-cut 
strawberries stored under high-oxygen atmospheres. J Food Sci 74(2):184-191

43. Fierascu RC, Temocico G, Fierascu I, Ortan A, Babeanu NE (2020) Fragaria genus: chemical composition and biological activities. Molecules 25(3):1-22

44. Kumar A, Ellis BE (2001) The phenylalanine ammonia-lyase gene family in raspberry. Structure, expression, and evolution. Plant Physiol 127(1):230-239
Publisher's Note Springer Nature remains neutral with regard to jurisdictional claims in published maps and institutional affiliations. 